\title{
Germinação in vitro de sementes e indução de calos em plântulas, cotilédones e anteras de porongo (Lagenaria siceraria (Mol.) Stand.) - Cucurbitaceae
}

\section{In vitro seed germination and calli induction in seedlings, cotyledons and anthers of bottle gourd (Lagenaria siceraria (Mol.) Stand.) - Cucurbitaceae}

\begin{abstract}
André Luís Lopes da Silva ${ }^{1 *}$; Dilson Antônio Bisognin ${ }^{2}$; Elci Terezinha Henz Franco ${ }^{3}$; Micheli Angélica Horbach ${ }^{4}$; Jefferson da Luz Costa ${ }^{5}$; Gessiel Newton Scheidt ${ }^{5}$; Sergio Augusto Oliveira Alves ${ }^{4}$ e Gilvano Ebling Brondani ${ }^{4}$

${ }^{1}$ Divisão de Engenharia de Bioprocessos e Biotecnologia; UFPR; 81531-970; Curitiba - PR - Brasil. ${ }^{2}$ Universidade Federal de Santa Maria, Avenida Roraima, $n^{o}$ 1.000, Caixa Postal 5.096, CEP 97105-900 Santa Maria, RS. ${ }^{3}$ Universidade Federal da Integração Latino-Americana, IMEA, 85867-970 - Foz do Iguacu, PR - Brasil. ${ }^{4}$ Departamento de Ciências florestais e Laboratório de Recursos Genéticos e Biotecnologia; Escola Superior de Agricultura Luiz de Queiroz - ESALQ/USP; 13418-900; Piracicaba - SP - Brasil. ${ }^{5}$ Departamento de Ciências Agrárias e Tecnológicas; Universidade Federal do Tocantins; 77402-970; Gurupi - TO - Brasil .
\end{abstract}

\begin{abstract}
The bottle gourd has economial importance for small and medium farms and great potential for industrial applications. Different strategies were tested for the in vitro seed germination, as luminosity, scarification, imbibition and addition of ANA (naftalenoacetic acid) and 2,4-D (2,4-Dichlorophenoxyacetic acid) on the culture medium. Later on, nodal segments and shoot tips were cultivated on medium supplemented with Fuji vitamins and cotyledonary explants cultivated in different concentrations of BAP (6-Benzylaminopurine) and ANA. For the calli induction, anthers were cultivated on medium contending 2,4-D and BAP. The germination of bottle gourd seeds occurred in the light and in the darkness, indicating neutral photoblastism. The scarification and the imbibition of whole seeds (seeds with tegument) did not facilitate the germination, in none of the treatments. ANA and 2,4-D in the variation of 0.12-1.0 mg. $\mathrm{L}^{-1}$ do not allow the in vitro germination of whole seeds on the culture medium. ANA and 2,4-D in the concentrations of $0.5 \mathrm{mg} . \mathrm{L}^{-1}$ and $0.25 \mathrm{mg} . \mathrm{L}^{-1}$, respectively, increased the in in vitro germination of nude seeds (seeds without tegument) of bottle gourd. The supplementation with Fuji vitamins allows the calli formation, mainly in the nodal segments. The calli formation in anthers (obtained from floral buttons contends 0.9 cm length) occurs on MS culture medium supplemented with 0.5 and $1.0 \mathrm{mg} . \mathrm{L}^{-1}$ of 2,4-D and BAP.
\end{abstract}

Key-words: Microspore, anther culture, callogenesis, Fuji vitamins, photoblastism; scarification

\section{INTRODUÇÃO}

A família Cucurbitaceae compreende mais de 120 gêneros com 800 espécies, que são predominantemente tropicais, embora algumas ocorram em regiões temperadas (Teppner, 2004). A espécie Lagenaria siceraria pertence à família Cucurbitaceae, sendo denominada nas regiões sulinas do Brasil como porongo. A maior importância desta espécie no sul do Brasil está relacionada com a produção de cuias, recipiente para a infusão da erva-mate (Ilex paraquariensis St. Hill.) ou chimarrão, uma bebida típica dessa região e dos países do Mercosul. O fruto do porongo também pode ser utilizado como tigela ou caixa de ressonância para a fabricação de instrumentos musicais, bem como matéria-prima para artesanato. As populações de polinização aberta de porongo apresentam grande diversidade

Author for correspondence: clonageinvitro@yahoo.com.br

J. Biotec. Biodivers. v. 3, N.4: pp. 117-126, Nov. 2012 
genética para formato de fruto (Bisognin e Marchezan, 1988; Bisognin e Storck, 2000; Lopes da Silva et al., 2002) e uma baixa percentagem de frutos industrializáveis, sendo que, entre dez populações avaliadas, a maior percentagem foi de apenas 73\% (Bisognin e Marchezan, 1988). Também não há nenhum programa de melhoramento genético estruturado para esta cultura. A cultura de tecidos é uma poderosa ferramenta que pode acelerar o melhoramento genético de uma espécie (Alves et al., 2011). Porém, protocolos eficientes de regeneração in vitro são imprescindíveis para a aplicação da cultura de tecidos no melhoramento genético.

Protocolos de cultivo in vitro foram estabelecidos para diversas espécies da família Cucurbitaceae utilizando-se diversos tipos de explantes. Pesquisas relacionadas ao cultivo in vitro de porongo já alcançaram alguns progressos quanto à germinação in vitro das sementes, propagação por cotilédones, segmentos nodais e brotações apicais e transformação genética (Han et al., 2004; 2005; Bisognin et al., 2008). Entretanto, ainda se encontram dificuldades de cultivo, pois as sementes de cucurbitáceas podem apresentar dormência ou germinação muito lenta (Casali et al., 1982). Além do tegumento, que representa um obstáculo para a germinação in vitro das sementes. A morfogênese in vitro pode seguir rotas embriogênicas ou organogênicas para a obtenção de mudas. A organogênese indireta foi reportada em Cucumis melo cv. Pusa Madhuras e em Benincasa hispida (Thomas e Sreejesh, 2004) onde folhas cotilédonares formaram calos, os quais posteriormente regeneraram gemas e brotos (Jain e More, 1992). Já em Momordica dioica plantas foram regeneradas via organogênese indireta utilizando explantes foliares (Devendra et al., 2009). No entanto, o processo de organogênese direta, onde gemas e brotações são formadas sem um prévio estádio de calo, foi descrita em Citrullus lanatus (Compton e Gray, 1994) e Cucurbita pepo (Ananthakrishnan et al., 2003; Lopes da Silva et al., 2006). A embriogênese indireta foi demonstrada em Cucumis sativus (Lou et al., 1996) e em Cucumis melo (Nakagawa et al., 2001).

A cultura de anteras permite a obtenção de plantas haplóides androgenéticas, o que permite a obtenção de linhagens homozigóticas em uma única etapa. No caso do porongo, a homozigose é de extrema importância para a fixação de características, como o formato do fruto, que é determinante para a indústria de cuia e, neste caso, do valor comercial da produção. Em cucurbitáceas, a androgênese já foi reportada em Cucurbita pepo (Metwally et al., 1998) e em Cucumis sativus (Ashok Kumar et al., 2003).

Este trabalhou objetivou avaliar alguns aspectos da germinação in vitro de sementes e da indução de calogênese em plântulas, cotilédones e anteras de porongo.

\section{MATERIAL E MÉTODOS}

Os experimentos foram realizados no Núcleo de Melhoramento e Propagação Vegetativa de Plantas do Departamento de Fitotecnia, Universidade Federal de Santa Maria, Rio Grande do Sul. Todos os cultivos foram mantidos em sala de crescimento com a temperatura de $25^{\circ} \pm 2^{\circ} \mathrm{C}$ e fotoperíodo de 16h, sob intensidade luminosa de aproximadamente $20 \mu \mathrm{M} \mathrm{m}^{-2} \mathrm{~S}^{-1}$ obtidas por lâmpadas fluorescentes brancas. As sementes utilizadas para os experimentos foram fermentadas à $25^{\circ} \mathrm{C}$ por $72 \mathrm{~h}$ na proporção de uma parte de semente e placenta para cinco partes de água (Bisognin et al., 1997).

As sementes sem tegumento foram imersas em álcool $70 \%$ por 1 min. e em solução de 3 a $4 \%$ de hipoclorito de sódio por $10 \mathrm{~min}$ de acordo com Bisognin et al. (2008).

\section{Influência da luminosidade, escarificação, embebição e de auxinas na germinação de sementes in vitro}

Para verificar a ocorrência de fotoblastismo, foram cultivadas sementes sem tegumento em meio de cultura sob condições de luminosidade (câmara de crescimento com fotoperíodo) e escuro (câmara de crescimento no escuro). $\mathrm{O}$ meio base de germinação de sementes utilizado foi o MS (Murashige e Skoog, 1962), suplementado com 30 g. $\mathrm{L}^{-1}$ de sacarose, solidificado com 7 g. $\mathrm{L}^{-1}$ de agar e $\mathrm{pH}$ de 5,7. A percentagem de germinação foi realizada após 15 dias de cultivo in vitro.

Foram verificados os efeitos da escarificação para induzir a germinação in vitro de sementes inteiras (sementes com tegumento). Os experimentos de escarificação contaram com quatro tratamentos em diferentes porções das sementes: (1) um corte realizado na região proximal da radícula, (2) dois cortes, um realizado na região proximal da radícula e outro na distal; (3) dois cortes realizados na região distal da radícula e (4) um corte realizado na região distal da radícula (Figura 1). 
O meio de cultura usado foi o meio base de germinação descrito acima. A percentagem de germinação foi realizada após 30 dias de cultivo in vitro.
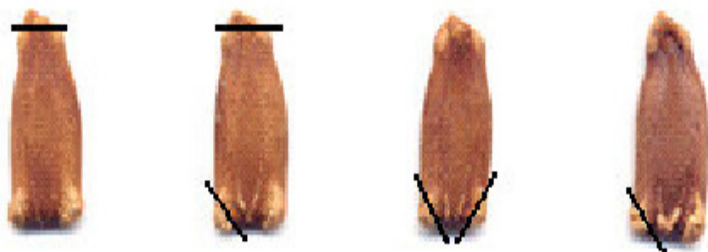

Figura 1- Escarificação de sementes de porongo em diferentes regiões.

Para verificar o efeito das auxinas na germinação in vitro, foram testadas sementes com e sem tegumento. Os tratamentos consistiram de concentrações de $0 ; 0,1 ; 0,25 ; 0,5$ e $1,0 \mathrm{mg} . \mathrm{L}^{-1}$ de ANA (ácido naftalenoacético) ou de 2,4 D (ácido 2,4 diclorofenoxiacético) adicionados ao meio de cultura. A avaliação consistiu na percentagem de sementes germinadas e da formação de calogênese. A avaliação da percentagem de germinação foi realizada após 22 dias e a de calogênese após 60 dias de cultivo in vitro.

\section{Efeitos das vitaminas Fuji na cultura de ápices caulinares e segmentos nodais}

Para o cultivo de ápices caulinares e segmentos nodais testou-se a adição de $2 \mathrm{~mL} . \mathrm{L}^{-1}$ de vitaminas Fuji (Lopes da Silva et al., 2009) ao meio base de germinação de sementes. Foram avaliados o número de folhas e brotos e a percentagem de calogênese e enraizamento após 20 dias de cultivo in vitro.

Organogênese direta em explantes cotiledonares Sementes germinadas em meio contendo água destilada, $30 \mathrm{~g} \mathrm{~L}^{-1}$ de sacarose e $7 \mathrm{~g} \mathrm{~L}^{-1}$ de agar, aos 13 dias de cultivo in vitro, foram utilizadas como fonte de cotilédones para os experimentos. Foram utilizados cotilédones inteiros com uma pequena porção de hipocótilo. Os tratamentos consistiram nas concentrações de 2,0;2,5;3,0;3,5 mg. $\mathrm{L}^{-1}$ de BAP (6-Benzilaminopurina), adicionados de 0,2 mg. $\mathrm{L}^{-1}$ de ANA. $\mathrm{O}$ meio de cultura utilizado foi $\mathrm{o}$ MS suplementado com $30 \mathrm{~g} \mathrm{~L}^{-1}$ de sacarose, solidificado com $7 \mathrm{~g} \mathrm{~L}^{-1}$ de Agar e $\mathrm{pH}$ de 5,7.

Já outros tratamentos foram realizados com diferentes fontes de explantes cotiledonares. Plântulas germinadas em meio contendo: $30 \mathrm{~g} \mathrm{~L}^{-1}$ de sacarose e $7 \mathrm{~g} \mathrm{~L}^{-1}$ de agar; e em meio $\mathrm{MS}$ suplementado com $30 \mathrm{~g} \mathrm{~L}^{-1}$ de sacarose, $7 \mathrm{~g} \mathrm{~L}^{-1}$ de agar e $0,5 \mathrm{mg} . \mathrm{L}^{-1}$ de ANA. Estes tratamentos foram suplementados com as concentrações de 3,0 mg. $\mathrm{L}^{-1}$ de BAP e $0,05 \mathrm{mg} . \mathrm{L}^{-1}$ de ANA.

Aos 13 dias de cultivo foram avaliadas a percentagem de cotilédones que formaram brotações, a percentagem de calogênese e de enraizamento dos cotilédones e o número de brotos formados por cotilédone.

\section{Cultura de anteras}

Anteras de plantas cultivadas no Jardim Botânico da UFSM da população Casco Fino Caciquense (Lopes da Silva et al., 2002), foram utilizadas nos experimentos. Para a análise histológica, anteras de porongo foram maceradas com o auxílio de um bastão de vidro e coradas com orseína acética $1 \%$. Os botões florais foram medidos do receptáculo até o final das pétalas, para correlacionar $\mathrm{o}$ tamanho do botão floral com o estádio de desenvolvimento do grão de pólen, utilizando o equipamento LAICA ESW para fotografar as lâminas.

Os botões florais foram coletados entre 10:15 e 10:30 da manhã, com o comprimento do dia de 13,41 horas e a temperatura entre $29^{\circ}$ a $31,2^{\circ} \mathrm{C}$. Botões florais de porongo foram retirados de plantas a campo e levadas para uma câmara de fluxo laminar e tiveram as anteras removidas e desinfestadas da seguinte forma, as anteras foram imersas em álcool $70 \%$ durante $5 \mathrm{~min}$., seguidas de duas lavagens com água destilada e autoclavada e imersas por 15 min. em solução de $\mathrm{NaOCl}(2 \%$ cloro ativo) adicionada de algumas gotas de detergente e lavadas três vezes com água destilada e autoclavada antes de serem inseridas no meio de cultivo.

Os tratamentos para a indução de calogênese consistiram das mesmas concentrações de $2,4 \mathrm{D}$ e BAP de $0 ; 0,5 ; 1,0$ e 2,0 mg. $\mathrm{L}^{-1}$. O meio de cultura utilizado foi o MS adicionado de $30 \mathrm{~g} . \mathrm{L}^{-1}$ de sacarose e 6 g.L $\mathrm{L}^{-1}$ de agar. Depois de inoculadas, as anteras foram colocadas em um refrigerador durante 24 horas, para ocorrer o sincronismo das divisões celulares. A indução de calogênese em anteras foi realizada no escuro e a avaliação realizada aos 40 dias de cultivo in vitro.

\section{Análise estatística}

O delineamento experimental utilizado nos experimentos foi o inteiramente casualisado, com quatro repetições de 10 explantes ou sementes. Os dados foram submetidos à análise de variância e as 
médias comparadas pelo teste de Tukey a 5\% de probabilidade de erro. Dados de contagem foram transformados para $\sqrt{x+0,5}$ e os de percentagem para arcoseno $\sqrt{x / 100}$. As análises foram realizadas com o auxílio do programa Genes (Cruz, 2001).

\section{RESULTADOS E DISCUSSÃO Influência da luminosidade, escarificação, embebição e de auxinas na germinação de sementes in vitro}

As sementes de porongo germinaram, tanto em condições de luminosidade quanto em condições de escuro (dados não apresentados), indicando que esta espécie possui fotoblastismo neutro, ao contrário de sementes de melancia que devem ser cultivadas no escuro (Compton, 2000). A escarificação por cortes não possibilitou a germinação das sementes inteiras de porongo em meio de cultura, em nenhuma das formas realizadas, demonstrando a dificuldade de germinação in vitro de sementes inteiras de porongo. Portanto, é necessário que o tegumento das sementes de porongo seja retirado para a germinação in vitro. A embebição das sementes nos intervalos utilizados nesse experimento não permitiu a germinação das sementes inteiras em meio de cultura.

Sementes inteiras (com tegumento) de porongo também não germinaram sobre a presença do 2,4 $\mathrm{D}$ ou de ANA. Possivelmente isto esteja relacionado à persistência de substâncias inibidoras da germinação presentes no tegumento, essas substâncias contidas no tegumento, quando cultivadas in vitro, podem ter dificuldade de difusão no meio de cultura sólido e permanecem associadas ao embrião, impedindo a germinação, visto que as mesmas sementes igualmente tratadas começam a germinar a partir de quatro dias em condições ex vitro (Bisognin et al., 1991).

A presença de ANA favoreceu a percentagem de germinação in vitro de sementes nuas. A maior percentagem de germinação atingida foi na concentração de $0,5 \mathrm{mg} . \mathrm{L}^{-1}$ de ANA, atingindo $27 \%$ após 22 dias de cultivo in vitro, cerca de 4 vezes mais do que na ausência de ANA (Figura 2). Resultados semelhantes foram encontrados em Carica papaya $\mathrm{L}$. onde a maior percentagem de germinação ocorreu na concentração de $5 \mu \mathrm{M}$ de
ANA, atingindo $80 \%$ de germinação in vitro (Bhattacharya e Khuspe, 2001). O ANA pode induzir a expressão de lipoxigenases, algumas destas enzimas produzem oxilipinas que parecem ser importantes moléculas sinalizadoras, que induzem respostas a estresses, tais como as provocadas por ataque de insetos, por infecções de fungos ou bactérias e por ferimentos causados por danos mecânicos. As oxilipinas podem influênciar a biossíntese do ácido jasmônico, o qual aumenta a habilidade da planta de responder a situações de estresse (Wang et al., 1999). A remoção mecânica do tegumento da semente frequentemente causa ferimentos nos tecidos, gerando estresse, o qual pode ser responsável pelo baixo percentual de germinação in vitro. Os resultados da suplementação do ANA no meio de cultura demonstraram um percentual de germinação superior à testemunha, o que sustenta esta hipótese.

Para a germinação in vitro de melancia foi utilizada a embebição de seis horas, seguida pela retirada do tegumento e semeadura in vitro (Compton, 2000). Neste caso, a embebição auxiliou o processo de remoção mecânica do tegumento de sementes de porongo. A redução da pressão osmótica pela diminuição da concentração de sacarose também não propiciou um aumento nos índices de germinação de sementes de porongo (Bisognin et al., 2008) e de mogango (Curcubita pepo L.) (Lopes da Silva et al., 2005).

Sobre a influência do ANA, nem todas as sementes produziram plântulas completas, foram observadas em todos os tratamentos, 50\% de plântulas completas, e a outra metade não apresentou formação de raízes. Possivelmente este efeito esteja associado ao fato da auxina induzir a biossíntese do etileno, o qual é um inibidor do crescimento de raízes (Taiz e Zeiger, 2004).

O 2,4 D é uma auxina sintética extremamente eficiente com relação a sua atividade química, pois não é tão rapidamente metabolizada pela planta quanto é o AIA (ácido indol-3-acético) (Taiz e Zeiger, 2004). O 2,4-D produziu um efeito semelhante ao ANA na germinação in vitro das sementes proporcionando um aumento na percentagem de germinação das sementes (Figura 2). 


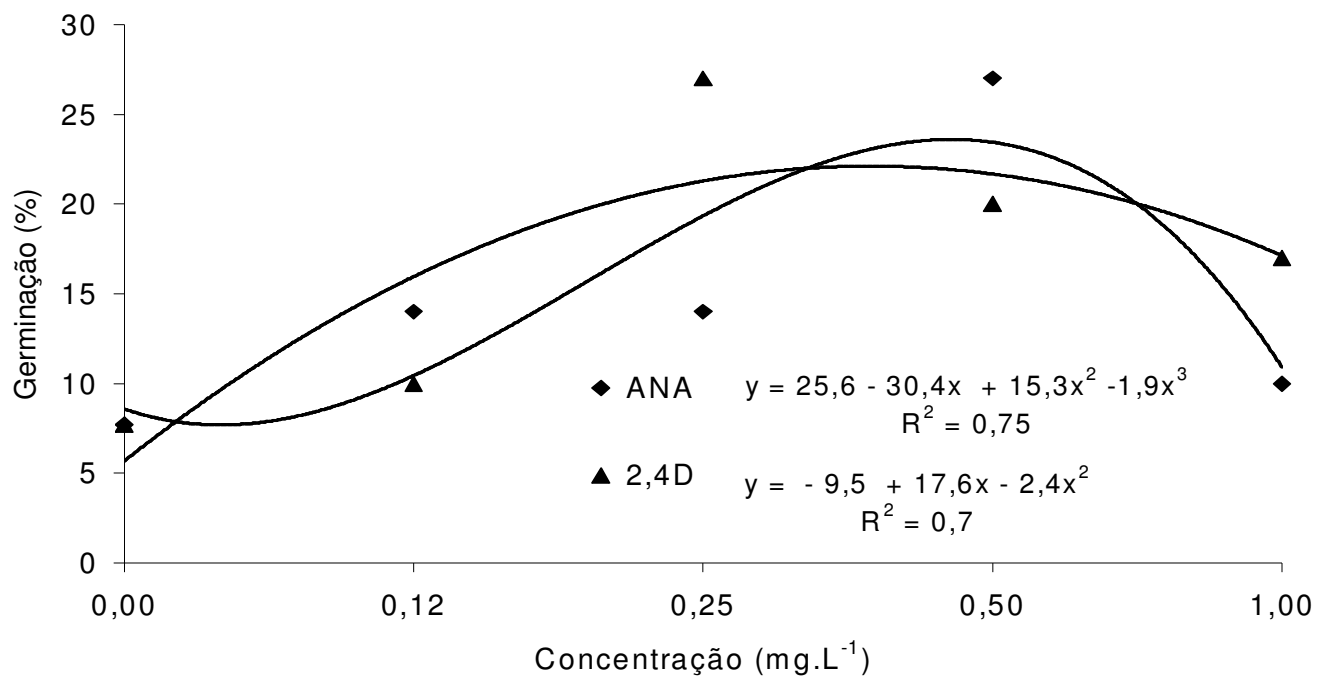

Figura 2- Efeitos do ácido naftalenoacético (ANA) e do ácido 2,4 diclorofenoxiacético (2,4-D) na germinação in vitro de sementes de porongo (Lagenaria siceraria (Mol.) Standl.) 22 dias após a semeadura in vitro.

As sementes germinadas sobre o efeito do 2,4 - D não produziram apenas plantas inteiras, sendo observadas também muitas plantas sem raízes.

A presença de ANA ou 2,4 D no meio de cultura não produziu nenhuma resposta de diferenciação ou desdiferenciação nos tecidos das sementes desprovidas de tegumento que não germinaram após 60 dias de cultivado in vitro. Não houve a indução de calos e não ocorreu embriogênese somática. Resultados diferentes foram observados em Carica papaya, onde concentrações de 1 a 20 $\mu \mathrm{M}$ de 2,4-D promoveram o desenvolvimento de calos em embriões desprovidos de tegumento (Bhattacharya e Khuspe, 2001).

Após 50 dias de cultivo foi observada a formação de calogênese nos hipocótilos das plântulas originadas das sementes nuas cultivadas tanto em ANA, quanto em 2,4 D (Figura 3). Este fato representa uma grande contribuição para a produção de calos em hipocótilos, abrindo perspectivas para o uso desta metodologia em estudos de morfogênese in vitro para esta espécie.

\section{Efeito das vitaminas Fuji na cultura de ápices caulinares e segmentos nodais}

No cultivo in vitro de ápices caulinares e segmentos nodais com vitaminas Fuji, não houve diferenças significativas entre os explantes quanto ao número de folhas e brotos (Tabela 1). Entretanto, a suplementação com as vitaminas Fuji induziu a formação de calos tanto de ápices caulinares quanto de segmentos nodais, sendo que a formação de calogênese foi maior nos explantes oriundos de segmentos nodais. Entretanto, a percentagem de enraizamento foi menor nos explantes de segmentos nodais, que tiveram uma maior indução de calo.

Tabela 1. Regeneração de ápices caulinares e segmentos nodais de porongo cultivadas in vitro com suplementação de vitaminas Fuji, após 20 dias.

\begin{tabular}{lcccc}
\hline Explantes & N. de folhas & N. de brotos & Calogênese (\%) & Enraizamento (\%) \\
\hline Ápice caulinar & $2,22 \mathrm{a}^{\mathrm{l}}$ & $1,55 \mathrm{a}$ & $22,2 \mathrm{~b}$ & $55,5 \mathrm{a}$ \\
Segmento nodal & $1,10 \mathrm{a}$ & $0,7 \mathrm{a}$ & $70,0 \mathrm{a}$ & $10,0 \mathrm{~b}$ \\
Média & 1,66 & 1,12 & 46,1 & 32,75
\end{tabular}

${ }^{1}$ Tratamentos com médias não seguidas pela mesma letra nas colunas diferem entre si pelo teste de Tukey a 5\% de probabilidade de erro.

Apesar de ter sido utilizada para maximizar o desenvolvimento vegetativo dos explantes, as vitaminas Fuji induziram a formação de calos nos explantes, principalmente nos segmentos nodais. A formação de calo indica que provavelmente as vitaminas Fuji podem ser utilizadas para 
desenvolver protocolos de organogênese indireta ou embriogênese indireta em porongo. As vitaminas Fuji possuem mio-inositol, promovendo a formação de calos em Nicotiana tabacum (Linsmaier e Skoog, 1967).

Tabela 2. Indução de brotações laterais em explantes cotiledonares de porongo aos 13 dias de cultivo in vitro.

\begin{tabular}{cccccc}
\hline \multicolumn{2}{c}{$\begin{array}{c}\text { Tratamentos } \\
\text { BAP }\left(\mathbf{m g . L} \mathbf{- 1}^{-\mathbf{1}}\right)\end{array}$} & $\begin{array}{c}\text { Calogênese } \\
\mathbf{A N A}\left(\mathbf{m g} . \mathbf{L}^{-\mathbf{1}}\right)\end{array}$ & $\begin{array}{c}\text { Brotações } \\
\text { laterais }(\boldsymbol{\%})\end{array}$ & $\begin{array}{c}\text { N. de } \\
\text { Brotos }\end{array}$ & $\begin{array}{c}\text { Enraizamento } \\
(\boldsymbol{\%})\end{array}$ \\
\hline 2,00 & 0,20 & $0,0 \mathrm{~b}^{1}$ & $10 \mathrm{~b}$ & $1,0 \mathrm{~b}$ & $75,0 \mathrm{ab}$ \\
2,50 & 0,20 & $0,0 \mathrm{~b}$ & $10 \mathrm{~b}$ & $1,0 \mathrm{~b}$ & $95,0 \mathrm{a}$ \\
3,00 & 0,20 & $0,0 \mathrm{~b}$ & $10 \mathrm{~b}$ & $1,0 \mathrm{~b}$ & $75,0 \mathrm{a}$ \\
3,50 & 0,20 & $0,0 \mathrm{~b}$ & $10 \mathrm{~b}$ & $1,0 \mathrm{~b}$ & $80,0 \mathrm{a}$ \\
$3,00^{2}$ & 0,05 & $0,0 \mathrm{~b}$ & $60,0 \mathrm{a}$ & $2,0 \mathrm{a}$ & $60,0 \mathrm{~b}$ \\
$3,00^{3}$ & 0,05 & $90,0 \mathrm{a}$ & $75,0 \mathrm{a}$ & $1,5 \mathrm{ab}$ & $100,0 \mathrm{a}$ \\
\hline
\end{tabular}

${ }^{1}$ Tratamentos com médias não seguidas pela mesma letra nas colunas diferem entre si pelo teste de Tukey a $5 \%$ de probabilidade de erro. ${ }^{2}$ Tratamento com cotilédones originados de plântulas cultivadas em meio MS somente. ${ }^{3}$ Tratamento com cotilédones originados de plântulas cultivadas em meio MS suplementado com $0,5 \mathrm{mg} \cdot \mathrm{L}^{-1} \mathrm{de}$ ANA.

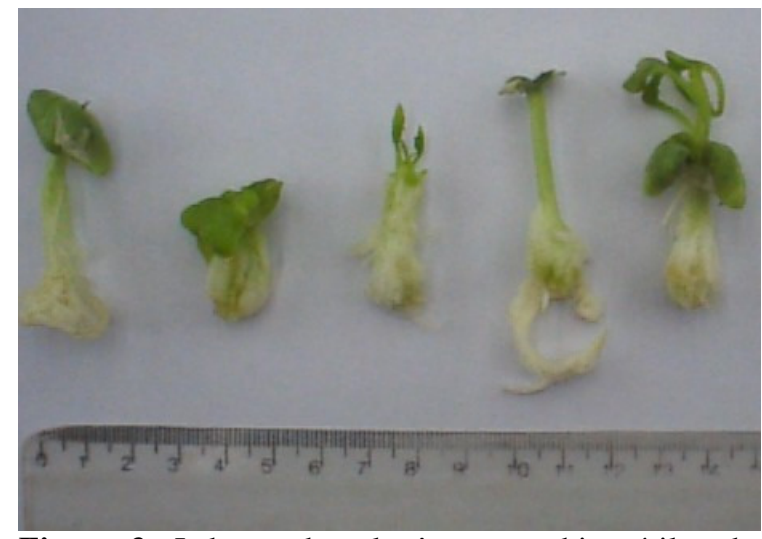

Figura 3- Indução de calogênese em hipocótilos de plântulas de Lagenaria siceraria originadas de sementes nuas após 50 dias de cultivo in vitro em meio MS suplementado com ácido 2,4 diclorofenoxiacético $(2,4-\mathrm{D})$.

Já em Dyckia agudensis e em Dyckia maritima as vitaminas Fuji auxiliaram no desenvolvimento de brotações múltiplas sem promover a formação de calos (Lopes da Silva et al., 2007; Lopes da Silva et al., 2008).

Organogênese direta em explantes cotiledonares As concentrações de 2,0 até $3,5 \mathrm{mg} . \mathrm{L}^{-1}$ de BAP associado a $0,2 \mathrm{mg} \cdot \mathrm{L}^{-1}$ de ANA promoveram apenas $10 \%$ de brotações laterais, uma brotação por cotilédone e o enraizamento variou de 75 a 95\% (Tabela 2). Entretanto, a redução do ANA de 0,2 mg. $\mathrm{L}^{-1}$ para $0,05 \mathrm{mg} \cdot \mathrm{L}^{-1^{3}}$ aumentou a percentagem de brotações laterais para $60-75 \%$ e 1,5-2 brotações por cotilédone e o enraizamento variou de 60 a 100\% (Tabela 2).

Cotilédones originados das sementes germinadas em meio MS suplementado com $0,5 \mathrm{mg} \cdot \mathrm{L}^{-1}$ de ANA e cultivados nas concentrações de 3,0 mg. $\mathrm{L}^{-1}$ de BAP e 0,05 mg. $\mathrm{L}^{-1}$ de ANA apresentaram brotações laterais e calos a partir da região basal do cotilédone. Provavelmente a formação de calos nesses cotilédones esteja associado ao nível endógeno residual de ANA obtido no meio de germinação com $0,5 \mathrm{mg} . \mathrm{L}^{-1}$ de ANA. O local da origem das brotações laterais parece ser a junção entre o segmento do hipocótilo com o cotilédone (Figura 4). Não foram observadas brotações laterais na região distal do cotilédone, o que também concorda com os resultados obtidos em cultivares de Cucurbirta pepo (Ananthakrishnan et al., 2003). O número de brotações não foi alterado pela origem do explante, porém o percentual de enraizamento foi maior em explantes cotiledonares de plântulas germinadas em meio com ANA $(0,5$ $\left.\mathrm{mg} . \mathrm{L}^{-1}\right)$. Em Momordica dioica a taxa de indução de calos foi de $80 \%$ em explantes foliares, em meio MS suplementado com 1,0 mg. $\mathrm{L}^{-1}$ 2,4-D + $2.0 \mathrm{mg} . \mathrm{L}^{-1}$ BAP (Devendra et al., 2009). Explantes foliares são mais responsivos a indução de calos e a subseqüente regeneração do que explantes nodais (Devendra et al., 2009). Os calos produzidos na base dos cotilédones podem ser utilizados em novos estudos morfogênicos, na 
tentativa de promover embriogênese ou organogênese para propagação clonal da espécie. $\mathrm{O}$ processo de morfogênese é controlado pelo balanço hormonal entre auxinas e citocininas. Este balanço hormonal é muito peculiar e está influenciado por vários fatores, como espécie, tipo de explante e o meio de cultura. Além disso, calos in vitro podem ser usados como fonte de metabólitos secundários com interesse industrial, com a grande vantagem de essas substâncias serem produzidas em condições controladas, permitindo um suprimento padronizado e de alta qualidade.

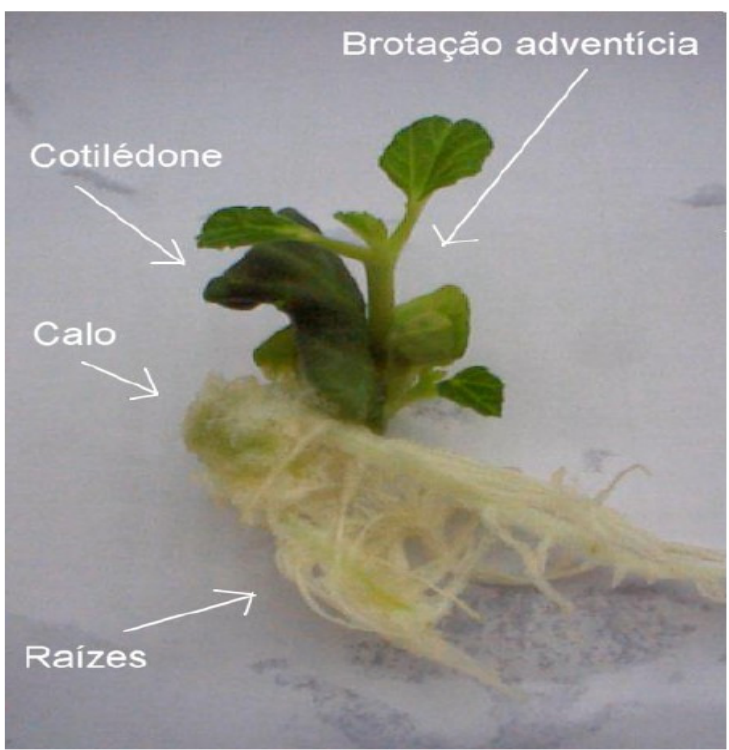

Figura 4- Indução de calogênese e brotações laterais em explante cotiledonar de porongo cultivado em meio MS suplementado com 3,0 mg. $\mathrm{L}^{-1}$ de 6Benzilaminopurina (BAP) e $0,05 \mathrm{mg} \cdot \mathrm{L}^{-1}$ de ácido naftalenoacético (ANA) aos 16 dias de cultivo (explante cotiledonar oriundo de plântulas germinadas em 0,5 mg. $\mathrm{L}^{-1}$ de ANA.

\section{Cultura de anteras}

A análise histológica dos grãos de pólen de porongo demonstrou a necessidade de coletar botões florais com $0,9 \mathrm{~cm}$ de comprimento, pois nesse tamanho o grão de pólen se encontra no estádio de micrósporo, indicado para a obtenção de plantas haplóides via cultura de anteras. Abaixo desse comprimento, até $0,7 \mathrm{~cm}$, foi observado o estádio de desenvolvimento em tétrades (Figura 5). A indução de calogênese em anteras de porongo ocorreu quando utilizadas simultaneamente as concentrações iguais de 2,4-D e BAP, tanto em 0,5 e 1,0 mg.L. $\mathrm{L}^{-1}$ (Tabela 3). No tratamento sem a adição de fitoreguladores não ocorreu formação de
Quando o nível de auxinas é elevado em relação ao de citocininas, ocorre a indução de embriogênese e o inverso induz a organogênese (Skoog e Miller, 1957).

calos. Para o cafeeiro, a adição de ANA e cinetina ao meio teve um efeito negativo na indução de calogênse, sendo que à medida que aumentou a concentração destes, a formação de calos diminuiu (Pasqual et al., 2002). Já com o porongo, ocorreu um aumento na formação de calos com o aumento das concentrações de 0,5 para $1,0 \mathrm{mg} . \mathrm{L}^{-1}$ de 2,4-D e BAP. Entretanto, quando aumentou a concentração para 2,0 mg.L $\mathrm{L}^{-1}$ de 2,4-D e BAP não ocorreu a formação de calogênese, indicando que esses níveis de fitoreguladores inibem a calogênse. A formação de calos compactos em antera de porongo pode ser observada na figura 6 .

Tabela 3. Indução de calogênese em anteras de porongo população Casco Fino Caciquense após 40 dias de cultivo in vitro.

\begin{tabular}{ccc}
\hline 2,4-D (mg.L $\left.\mathbf{~}^{-1}\right)$ & BAP (mg. $\left.\mathbf{L}^{-1}\right)$ & Calogênese (\%) \\
\hline 0,0 & 0,0 & $0 \mathrm{~b}^{1}$ \\
0,5 & 0,5 & $10 \mathrm{a}$ \\
1,0 & 1,0 & $20 \mathrm{a}$ \\
2,0 & 2,0 & $0 \mathrm{~b}$
\end{tabular}

\footnotetext{
${ }^{1}$ Tratamentos com médias não seguidas pela mesma letra nas colunas diferem entre si pelo teste de Tukey a 5\% de probabilidade de erro.
}

\section{CONCLUSÕES}

A germinação de sementes de porongo ocorre tanto em condições de luminosidade quanto no escuro, indicando fotoblastismo neutro. A escarificação e a embebição de sementes inteiras não possibilita a germinação, em nenhum dos tratamentos. O ANA e o 2,4 D na escala de 0,12$1,0 \mathrm{mg} \cdot \mathrm{L}^{-1}$ não permitem a germinação in vitro de sementes inteiras em meio de cultura. $\mathrm{O}$ ANA e o 2,4-D nas concentrações de $0,5 \mathrm{mg} \cdot \mathrm{L}^{-1}$ e 0,25 $\mathrm{mg} . \mathrm{L}^{-1}, \quad$ respectivamente proporcionam um aumento no percentual de germinação in vitro de sementes nuas de porongo. A suplementação do meio de cultura com vitaminas Fuji favorece a formação de calos, principalmente em segmentos nodais. A formação de calos em anteras (retiradas de botões florais contendo $0,9 \mathrm{~cm}$ de comprimento) ocorre em meio MS com $0,5 \mathrm{mg} . \mathrm{L}^{-1}$ de 2,4 D e BAP e 1,0 mg. $\mathrm{L}^{-1}$ de 2,4 D e BAP. 

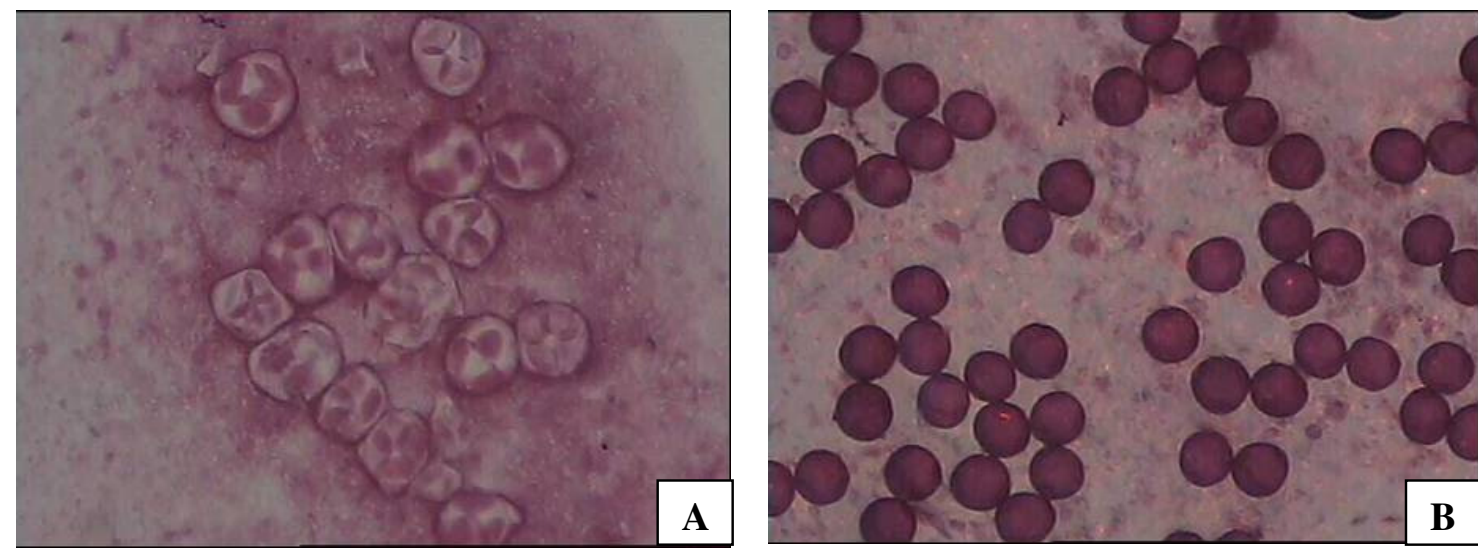

Figura 5- Grãos de pólen de Lagenaria siceraria: (A) em estádio de tétrades, coletadas de botões florais com 0,7 cm de comprimento; (B) em estádio de micrósporos, coletadas de botões florais com 0,9 cm de comprimento.

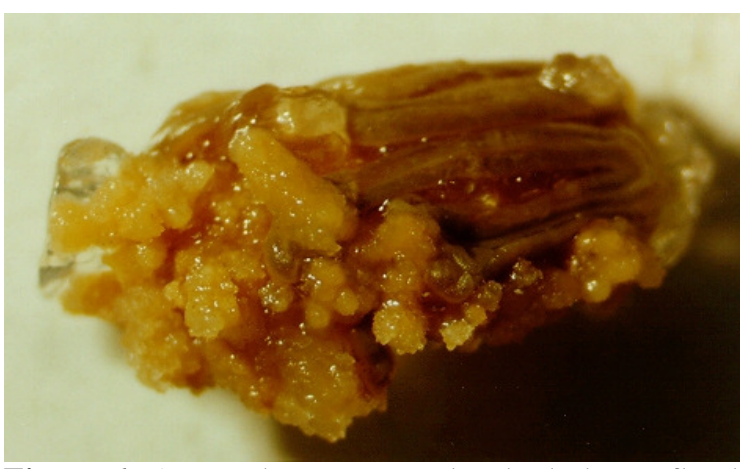

Figura 6- Antera de porongo coletada de botão floral com $0,9 \mathrm{~cm}$ de comprimento, apresentando calos compactos aos 40 dias de cultivo in vitro.

\section{RESUMO}

O porongo representa uma planta com importância econômica para pequenos e médios produtores rurais e com grande potencial para aplicações industriais. Foram testadas diferentes estratégias para a germinação in vitro de sementes, como luminosidade, escarificação, embebição e adição de ANA (ácido naftalenoacético) e 2,4-D (ácido 2,4 diclorofenoxiacético) ao meio de cultivo. Posteriormente, segmentos nodais e ápices caulinares foram cultivados em meio com vitaminas Fuji e explantes cotiledonares cultivados em diferentes concentrações de BAP (6-Benzilaminopurina) e ANA. Para a indução de calos, foram cultivadas anteras em meio contendo 2,4-D e BAP. A germinação de sementes de porongo ocorre tanto no claro como no escuro, indicando fotoblastismo neutro. A escarificação e a embebição de sementes inteiras não possibilitam a germinação, em nenhum dos tratamentos. O ANA e o 2,4-D na variação de $0,12-1,0 \mathrm{mg} \cdot \mathrm{L}^{-1}$ não permitem a germinação in vitro de sementes inteiras em meio de cultura. O ANA e o 2,4-D nas concentrações de 0,5 $\mathrm{mg} . \mathrm{L}^{-1}$ e $0,25 \mathrm{mg} . \mathrm{L}^{-1}$, respectivamente proporcionam um aumento no percentual de germinação in vitro de sementes nuas de porongo. $\mathrm{Na}$ suplementação com vitaminas Fuji foi observada a formação de calos, principalmente em segmentos nodais. A formação de calos em anteras (obtidas de botões florais contendo 0,9 cm de comprimento) ocorre em meio de cultura MS suplementado com 0,5 e 1,0 mg. $\mathrm{L}^{-1}$ de 2,4-D e BAP.

Palavras-chave: Micrósporo; cultura de anteras; calogênese; vitaminas Fuji; fotoblastismo; escarificação

\section{REFERÊNCIAS}

Alves, S. A. O.; Lemos, O. F.; Santos Filho, B. G.; Lopes Da Silva, A. L. (2011), In vitro embryo rescue of interspecific hybrids of oil palm (Elaeis oleifera $\mathrm{x}$ Elaeis guineensis). Journal of Biotechnology and Biodiversity, 2, 1-6.

Ananthakrishnan, G.; Xia, X.; Elman, C. Singer, S.; Paris, H. S.; Gal-On, A.; Gaba, V. (2003), Shoot production in squash (Cucurbita pepo) by in vitro organogenesis. Plant Cell Reports, 21, 739746.

Ashok Kumar, H. G. H. N.; Murthy, H. N.; Paek, K. Y. (2003), Embryogenesis and plant regeneration from anther cultures of Cucumis sativus L. Scientia Horticulturae, 98, 213-222.

Bhattacharya, J. e Khuspe, S. S. (2001), In vitro and in vivo germination of Papaya (Carica papaya L.) seeds. Scientia Horticulture, 91, 39-49.

Bisognin, D. A. e Marchezan, E. (1988), Avaliação de algumas populações de porongo Lagenaria siceraria (Mol.) Standl. - cultivadas na região de Santa Maria, RS. Revista do Centro de Ciências Rurais, 18, 201-207. 
Bisognin, D. A.; Irigon, D. L.; Martinazzo, A. A. (19910, Teste de germinação em porongo Lagenaria siceraria (Mol.) Standl. Ciência Rural, 21, 159-167.

Bisognin, D. A.; Menezes, N. L.; Bellé, R. A.; Albini, A. M. (1997), Efeito do tamanho de fruto e do método de extração na qualidade fisiológica de sementes de porongo. Ciência Rural, 27, 13-19.

Bisognin, D. A. e Storck, L. (2000), Estimativa dos componentes de variância e herdabilidade para formato do fruto em porongo - Lagenaria siceraria (Mol.) Standl. Ciência Rural, 30, 593597.

Bisognin, D. A.; Lopes Da Silva, A. L.; Horback, M. A.; Girotto, J.; Barriquello, C. J. (2008), Germinação e propagação in vitro de porongo. Ciência Rural, 38, 332-339.

Casali, V. W. D.; Saturnino, H. M.; Pedrosa, J. F. (1982), Botânica e origem das cucurbitáceas. In: EPAMIG. As cucurbitáceas. Informe Agropecuário, 8, 22-23.

Compton, M. E. e Gray, D. J. (1994), Adventitious shoot organogenesis and plant regeneration from cotyledons of tetraploid watermelon. HortScience, 29, 211-213.

Compton, M. E. (2000), Interaction between explant size and cultivar affects shoot organogenic competence of watermelon cotyledons. HortScience, 35, 749-750.

Cruz, C. D. Programa Genes: versão Windows; aplicativo computacional em genética e estatística. Viçosa, MG: UFV, Imprensa Universitária, 2001, 648p.

Devendra, N. K.; Subhash, B.; Seetharam, Y. N. (2009), Callus growth and plant regeneration in Momordica dioica (Roxb.) Willd. Cucurbitaceae. American-Eurasian Journal of Sustainable Agriculture, 3, 743-748.

Han, J. S.; Oh, D. G.; Mok, I. G.; Park, H. G.; Kim, C. K. (2004), Efficient plant regeneration from cotyledon explants of bottle gourd (Lagenaria siceraria Standl.). Plant Cell Reports, 23, 291-296.
Han, J. S.; Kim, C. K.; Park, S. H.; Hirschi, K. D.; Mok, I. G. (2005), Agrobacterium-mediated transformation of bottle gourd (Lagenaria siceraria Standl.). Plant Cell Reports, 23, 692698.

Jain, J. e More, T. A. (1992), In vitro regeneration in Cucumis melo cv. Pusa Madhuras. Cucurbit Genetics Cooperative Reports, 15, 62-64.

Linsmaier, E. M. e Skoog, F. (1967), Organic growth factor requirement in relation to cytokinin in 'normal' and 'mutant' strains of tobacco callus. Planta, 72, 146-154.

Lopes da Silva, A. L.; Záchia, R. A.; Bisognin, D. A.; Budke, J. C. (2002), Coleta e caracterização morfológica de populações de porongo Lagenaria siceraria (Mol.) Standl. Cucurbitaceae. Ciência e Natura, 24, 91-100.

Lopes da Silva, A. L.; Bisognin, D. A.; Barriquello, C. J.; Ritter, C. E. L. (2005), Germinação in vitro de sementes de mogango (Cucurbita pepo L.) - Cucurbitaceae. Ciência e Natura, 27, 19-28.

Lopes da Silva, A. L.; Bisognin, D. A.; Barriquello, C. J.; Girotto, J. (2006), Organogênese direta de explantes cotiledonares e regeneração de plantas de mogango. Ciência Rural, 36, 992-995.

Lopes da Silva, A. L.; Dornelles, E. B.; Bisognin, D. A.; Franco, E. T. H.; Horbach, M. A. (2007), Micropropagation of Dyckia agudensis Irgang \& Sobral an exctinction threatened bromeliad. Iheringia Série Botânica, 62, 39-43.

Lopes da Silva, A. L.; Franco, E. T. H.; Dornelles, E. B.; Gesing, J. P. A.(2008), Micropropagação de Dyckia maritima Baker - Bromeliaceae. Iheringia Série Botânica, 63, 135-138.

Lopes da Silva, A. L.; Franco, E. T. H.; Dornelles, E. B.; Reichert Bortoli, C. L.; Quoirin, M. (2009), In vitro multiplication of Vriesia scalaris $\mathrm{E}$. Morrem (Bromeliaceae). Iheringia Série Botânica, 64, 151-156.

Lou, H.; Obara-Okeyo, P.; Tamaki, M. Kaki, S. (1996), Influence of sucrose concentration on in vitro morphogenesis in cultured cucumber 
cotyledon explants, Journal of Horticultural Science, 71, 497-502.

Metwally, E. I.; Moustafa, S. A. El-Sawy, B. I.; Shalaby, T. A. (1998), Haploid plantlets derived by anther culture of Cucurbita pepo. Plant Cell Tissue and Organ Culture, 52, 171-176.

Murashige, T. e Skoog, F. (1962), A revised medium for rapid growth and bioassays with tobacco tissue cultures. Physiologia Plantarum, 15, 473-497.

Nakagawa, H.; Saijyo, T.; Yamauchi, N.; Shigyo, M.; Kako, S.; Ito, A. (2001), Effects of sugar and abscisic acid on somatic embryogenesis from melon (Cucumis melo L.) expanded cotyledon. Scientia Horticulturae, 90, 85-92.

Pasqual, M.; Maciel. A. L. R.; Campos, K. P.; Santos, E. C.; Campos, J. R. C. (2000), Indução de calos em anteras de café (Coffea arabica L.) cultivadas in vitro. Ciência e Agrotecnologia, 26, 71-76.
Skoog, F. e Miller, C. O. (1957), Chemical regulation of growth and organ formation in plant cultured in vitro. Symposium of Society for Experimental Biology, 11, 118-131.

Taiz, L. e Zeiger, E. Fisiologia Vegetal. Porto Alegre: Artmed, 2004, 719p.

Teppner, H. (2004), Notes on Lagenaria and Cucurbita (Cucurbitaceae) - Review and new contributions. Phyton, 44, 245-308.

Thomas, T. D. e Sreejesh, K. R. (2004), Callus induction and plant regeneration from cotyledonary explants of ash gourd (Benincasa hispida L.). Scientia Horticulturae, 100, 359-367.

Wang, C.; Järlfors, U.; Hildebrand, D. F. (1999), Regulation and subcellular localization of auxininduced lipoxygenases. Plant Science, 148, 147153. 